\title{
Effects of Selected Wound Dressings and Remedies on Planktonic Bacteria and Bacterial Biofilms of Staphylococcus aureus and Pseudomonas aeruginosa
}

\section{Mamdouh A. Bukhari ${ }^{1}$, AL Quthami Khalid2 ${ }^{2}$, Milton Wainwright ${ }^{3}$, Soliman A. M. Abdelrazak}

\author{
${ }^{1}$ Public Health Lab. Moh. Makkah, Saudi Arabia \\ ${ }^{2}$ Regional Laboratory,Moh, Makkak, Saudi Arabia \\ ${ }^{3}$ Department of Molecular Biology and Biotechnology, University of Sheffield, Sheffield, S10 2TN, United \\ Kingdom
}

\begin{abstract}
The overall aim of this research is to evaluate the effect of some approaches of treating wounds and the use of wound dressings of on the planktonic bacteria and bacterial biofilms of Staphylococcus aureus and Pseudomonas aeruginosa, two major bacterial species found in wounds. The wound treatments were dressings containing either honey or silver, and commercial hand gels with alcohol. Results indicate that dressings that contain Manuka honey were efficacious against planktonic bacteria of $S$. aureus, whereas, dressings with silver were most effective against planktonic Pseudomonas aeruginosa. Panaderm (antibiotic) showed the strongest activity against both planktonic $S$. aureus and $P$. aeruginosa. The effect of wound treatments on non-established and established bacterial biofilms after 24 and 48 hours after application, show that dressings were effective against the biofilm of $S$. aureus. However, a non-adherent dressing with Activon Manuka Honey was ineffective against Pseudomonas aeruginosa biofilm. Overall, except for hand gels, the wound remedies tested show remarkable activity against the biofilms of $S$. aureus and $P$. aeruginosa.
\end{abstract}

\section{Introduction}

Wounds arise when the skin suffers internal or external injuries. External injuries involve cutting or piercing the skin, which causes an open wound. Internal injuries are caused by contusion of the skin that generates a closed wound. Wounds provide bacteria with an opportunity to invade the body, although wound entry can be managed through methods such as cleaning, closure, and application of dressing that contain antibiotics. Antibiotics can fail in most cases in chronic wounds with the formation of bacterial biofilm that are very hard to eliminate and expensive to treat (Bjarnsholt et al., 2008, Davis et al., 2008, James et al., 2008).

Dressings provide good healing and dry conditions where wounds are protected from contamination, in addition to the antimicrobial activity added by the dressing (Benbow, 2005).

The effects of silver dressing against pathogenic bacteria differ from that of antibiotics. Silver dressings act on the respiratory system of the cell, transmembrane electrolyte transport, cell membrane integrity, enzyme activities and cell proliferation (Lansdown, 2002). In addition, silver dressings lessen the ability of bacteria to adhere to surfaces (Chaw et al., 2005, Klueh et al., 2000), and acts against the formation of bacterial biofilm (Percival et al., 2007).

Manuka honey is widely used in wound dressing. Manuka honey has shown marked activity on wound because of its osmolarity, acidity, and content of hydrogen peroxide content, flavonoids, phenolic acid compounds, and methylglyoxal, a unique compound (Moore et al., 2001, Gethin et al., 2008, Kwakman et al., 2010, Escriche et al., 2013, Kwakman and Zaat, 2012).

Treatment with honey was used successfully in wounds, ulcers, abdominal pain and burns (Sharp, 2009, Topham, 2002). It was reported that Medihoney ${ }^{\mathrm{TM}}$ dressing succeeded in curing some 
chronic wounds after drug therapy failure aftrer 12 weeks (Dunford and Hanano, 2004).

In this study, the effect of different wound dressings and wound remedies on planktonic bacteria and bacterial biofilms was studied.

\section{Materials and Methods}

Two types of the most common causing wound infecting bacteria were used in the tests, namely Staphylococcus aureus SH1000 and Pseudomonas aeruginosa PA01. The bacteria were grown in five different media. Biofilms of $S$. aureus were grown on brain and heart infusion agar (BHI), while biofilms of $P$. aeruginosa were grown on agar base ISO 13720 (ISO). Nutrient agar (NA) was used for bacterial plate counts, while nutrient broth and Muller Hinton Agar (MHA) were employed for the sensitivity tests.

\section{Effects of dressings and creams on $S$. aures and $\boldsymbol{P}$.} aeruginosa development

Four types of wound dressings were tested on planktonic bacteria as follows: (1) Askina ${ }^{\circledR}$ Calgitrol ${ }^{\circledR}$ Ag, (2) Actilite ${ }^{\circledR}$ (a non-adherent dressing containing Activon Manuka honey), (3) Algivon ${ }^{\circledR}$ alginate containing active Manuka honey, and (4) Algivon $^{\circledR}$ alginate dressing impregnated with $100 \%$ Manuka honey. The dressings were cut into $12 \mathrm{~mm}$ pieces and kept in sterile, empty Petri dishes until use. Muller Hinton agar plates were inoculated with bacterial broth and incubated at $37^{\circ} \mathrm{C}$ for 30 minutes. The dressings were then arranged equidistantly on the plate and incubated at $37^{\circ} \mathrm{C}$ for 24 hours.

Three types of wound creams, Panaderm ${ }^{\circledR}$, Activon ${ }^{\circledR}$ Manuka honey and Flamazine, and a hand sterilizer (with isopropanol) were tested for their antibacterial properties. Panaderm cream consists of three types of antibiotics (neomycin sulphate $2.5 \mathrm{mg}$, Nystatin 100.000 units and gramicidin $0.25 \mathrm{mg}$ ), while Flamazine contains silver as active ingredient. The creams and the hand gel were dispensed in 4 wells on the MHA plates previously inoculated with bacterial suspension. The plates were incubated for 24 hours at $37^{\circ} \mathrm{C}$.

The activities of the dressings Askina ${ }^{\circledR}$ Calgitrol ${ }^{\circledR}$ Ag, Actilite $^{\circledR}$ and Algivon ${ }^{\circledR}$ impregnated with $100 \%$ Manuka honey were tested against biofilm formation, and established biofilm 24 and 48 hours after dressing application.

\section{Colony biofilm assay}

Nitrocellulose membranes of $25 \mathrm{~mm}$ diameter (Millipore) were used to create the biofilm. Development of biofilms as described in Protocol 3 described by Merritt et al., (2005) was followed.
Membranes were soaked into phosphate buffer solution for 24 hours and then transferred into adjusted bacterial suspension media and left for 15 minutes. Using sterile forceps, membranes were placed onto the surface of nutrient agar plates and incubated side down at $37{ }^{\circ} \mathrm{C}$ for 48 hours, transferred to new plates and incubated for additional 48 hours incubation. After 96 hours, three membranes were removed from the media, and washed in sterile phosphate buffer to remove all planktonic cells. Washed membranes were transferred separately into $10 \mathrm{ml}$ tubes with sterile phosphate buffer solution, and then transferred to a sonicator bath for 1 hour to release all viable cells. The tubes were vortexed for 30 seconds to homogenize the suspension. One $\mathrm{ml}$ of the suspension was transferred to $9 \mathrm{ml}$ phosphate buffer to make dilutions of $10^{-1}$; serial dilutions were then made up to $10^{-6}$. Aliquots $(100 \mu \mathrm{l})$ were taken from all tubes and spread on nutrient agar plate by use of a spreader and incubated for 24 hours to obtain the colony forming unit count (CFU). All counts are given as the mean of triplicates.

Remaining membranes from the agar plates were removed after incubation for 96 hours, and then washed with sterile phosphate buffer saline solution. Washed membranes were then distributed equidistant from each other onto new agar plates. Wound dressings were cut into squares and placed on the plates with the membranes. The plate thus contained four membranes with three pieces of the same dressings as follows:

1. Negative control - membrane soaked in phosphate buffer without bacteria

2. Non-established biofilm - membrane neutralized in phosphate buffer for 24 hours then soaked in bacterial suspension for 15 minutes

3. Established biofilm- membrane with established biofilm, and tested after 24 hours

4. Established biofilm- membrane with established biofilm and tested after 48 hours

All the determinations were done in triplicate.

Twenty-four hours after incubation, all dressings were removed except one which was examined after 48 hours. After taking out the membranes from the media, these were washed in sterile phosphate buffer to remove all planktonic cells, and then transferred into $10 \mathrm{ml}$ separate tubes of sterile phosphate buffer solution, and then transferred to a sonicator bath for 1 hour to release all viable cells. Tubes were vortexed for 30 seconds to homogenize the suspension. One $\mathrm{ml}$ was then transferred to $9 \mathrm{ml}$ phosphate buffer to make a dilution of $10^{-1}$, serial dilutions were then 
made up to $10^{-6}$. An aliquot $(100 \mu 1)$ was taken from all tubes and spread on nutrient agar plate and incubated for 24 hours to obtain the colony forming unit (CFU) of the main tubes. All counts are the means of triplicates. The same procedure was performed on the dressings sampled after 48 hours.

\section{Determination of the effect of wound creams on bacterial biofilms}

Four wound treatments, Panaderm ${ }^{\circledR}$ cream (effective against Gram negative and Gram positive bacteria as well as fungi), Flamazine ${ }^{\circledR}$ cream (silver as active component), Activon ${ }^{\circledR}$ cream (active component is Manuka honey), and a hand sterilizing agent.The minimum biofilm eradication concentration (MBEC) was determined using the $\mathrm{MBEC}^{\mathrm{TM}}$ High-Throughput (HTP) Assay (Innovotech, Canada). In summary, more than 7 colonies of the same morphological appearance of a fresh subculture of the test bacteria were picked off with a sterile loop and dipped into $1.5 \mathrm{ml}$ sterile nutrient broth. One $\mathrm{ml}$ of prepared inocula was transferred into $29 \mathrm{ml}$ of nutrient broth. This 30 -fold dilution of the 1.0 McFarland standard serves as the inocula for the MBEC plate. A new MBEC plate was opened and the first row and the second row of pegs were removed by using sterile metal pliers to use these rows as negative controls afterward. Twenty-two $\mathrm{ml}$ of the previous prepared fold dilution was added to the MBEC plate and incubated in $37^{\circ} \mathrm{C}$ for 48 hours in the case of $S$. aureus and 96 hours for $P$. aeruginosa (Wirtanen et al., 2001).

Concentrations of the treatment were prepared previously in sterile tubes and then transferred to wells depending on the used treatment. The vertical well line was used for one type of honey from the third row to the eleventh row. The test for each type of honey was done in duplicate. The twelfth row used as positive control. A sterile microtiter plate with 200 $\mu \mathrm{l}$ of physiological saline was setup in every well. This plate was used to rinse the pegs to remove loosely adherent planktonic cells from the biofilm.

After the incubation period of the MBEC plate, the peg lid from the trough was removed and the pegs submerged in the wells of the rinse plate. The peg lid was let for 1 to 2 minutes. This step was repeated in a new rinse plate. After washing, the peg lid of the MBEC was inserted into the challenge plate properly and incubated at $37^{\circ} \mathrm{C}$ for 24hours. After the incubation period, the peg lid of the MBEC plate was washed twice using the same mentioned protocol in two different rinse plates. A 96-well plate was prepared by adding $200 \mu \mathrm{l}$ of nutrient broth in all wells and this was the recovery plate. The washed MBEC plate was transferred to the recovery plate and closed tightly to prevent any possibility of the contamination. The plate was transferred onto the tray of the sonicator. The plate was left for 1 hour to allow the vibrations to disrupt the biofilms from the surface of the remaining pegs into the recovery plate. The plate was then incubated for 24 hours and checked for the visible growth.

The horizontal wells were used for one type of treatment from the ninth column to the twelfth column. The test for each type of treatment was done in the whole column. The fifth and sixth columns were removed by using sterile metal pliers to use these rows as negative controls afterward whereas the first, second and third columns were used as positive controls.

\section{Results and Discussion}

a. Effects of some wound dressing on planktonic bacteria of Staphylococcus aureus and Pseudomonas aeruginosa

When Staphylococcus aureus bacteria was tested against dressings impregnated with honey, they showed greater activity compared with that of silver dressing which agrees with the findings of Kostenko et al. (2010) about the diversity of effectiveness of dressings that associated with dressing base material. The activity of Actilite was highest, followed by Algivon with active Manuka honey and then Algivon with 100\% Manuka honey (Figure 1). However, silver dressing was more effective in inhibiting the growth of Pseudomonas aeruginosa compared with Manuka honey (Figure 2). 


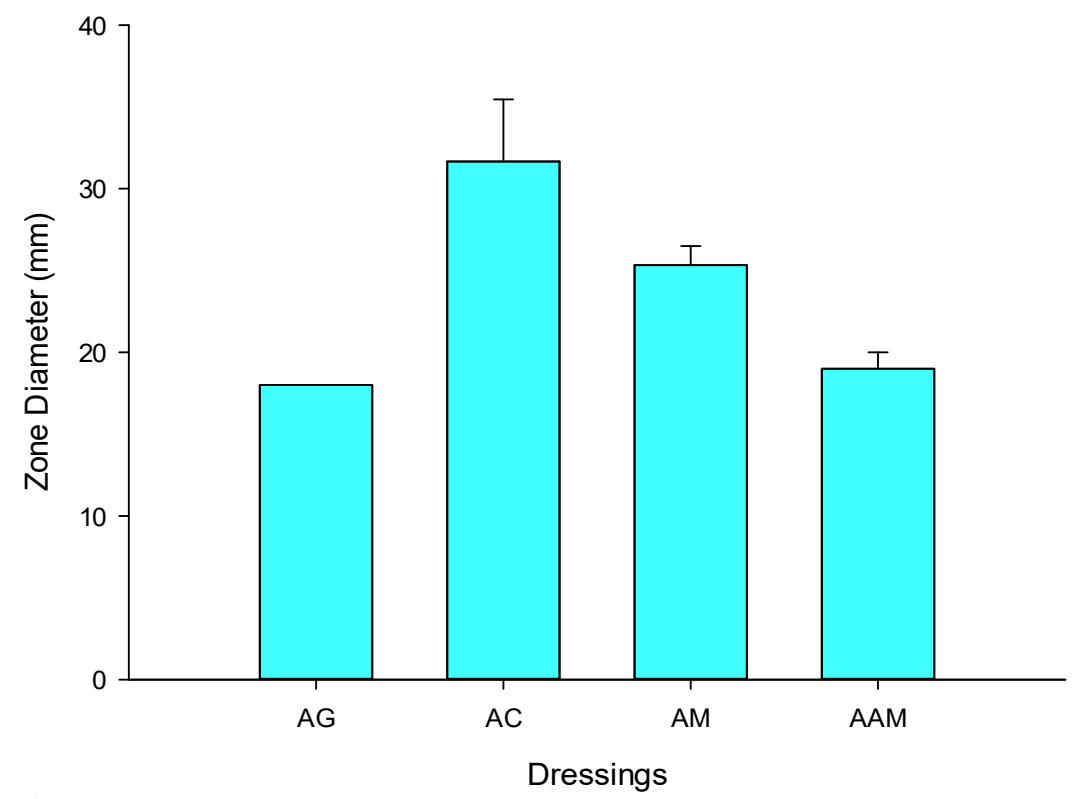

Figure 1. Effect of wound dressings on the growth of Staphylococcus aureus. Ag-Askina Calgitrol Ag; AC- Actilite; AM- Algivon (alginate containing Activon Manuka honey); AAM -Algivon (alginate dressing impregnated with 100\% Manuka honey).

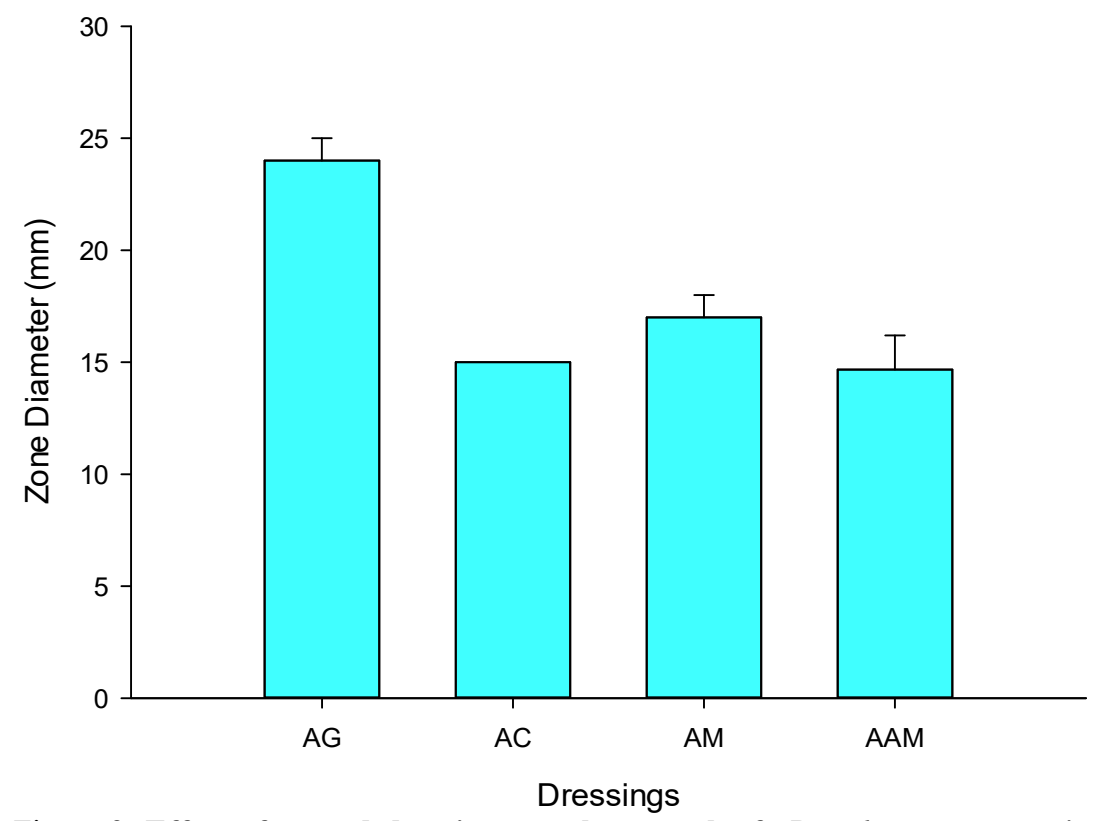

Figure 2. Effect of wound dressings on the growth of Pseudomonas aeruginosa. Ag-Askina Calgitrol Ag; AC- Actilite; AM- Algivon (alginate containing Activon Manuka honey); AAM -Algivon (alginate dressing impregnated with $100 \%$ Manuka honey). 
Effects of Selected Wound Dressings and Remedies on Planktonic Bacteria and Bacterial Biofilms of Staphylococcus aureus and Pseudomonas aeruginosa

b. Effects of some wound remedies on planktonic bacteria of Staphylococcus aureus and Pseudomonas aeruginosa

Some wound treatments including antibiotics, honey, silver and hand gel were tested on the viable cells of $S$. aureus and Ps. aeruginosa. Panaderm was the most effective one against $S$. aureus and $P$. aeruginosa. Activon Manuka showed remarkable activity against $S$. aureus and intermediate activity against $P$. aeruginosa. Flamazine exhibited moderate activity against $S$. aureus and $P$. aeruginosa. The hand gel showed the least activity on both types of bacteria (Figures 3 and 4).

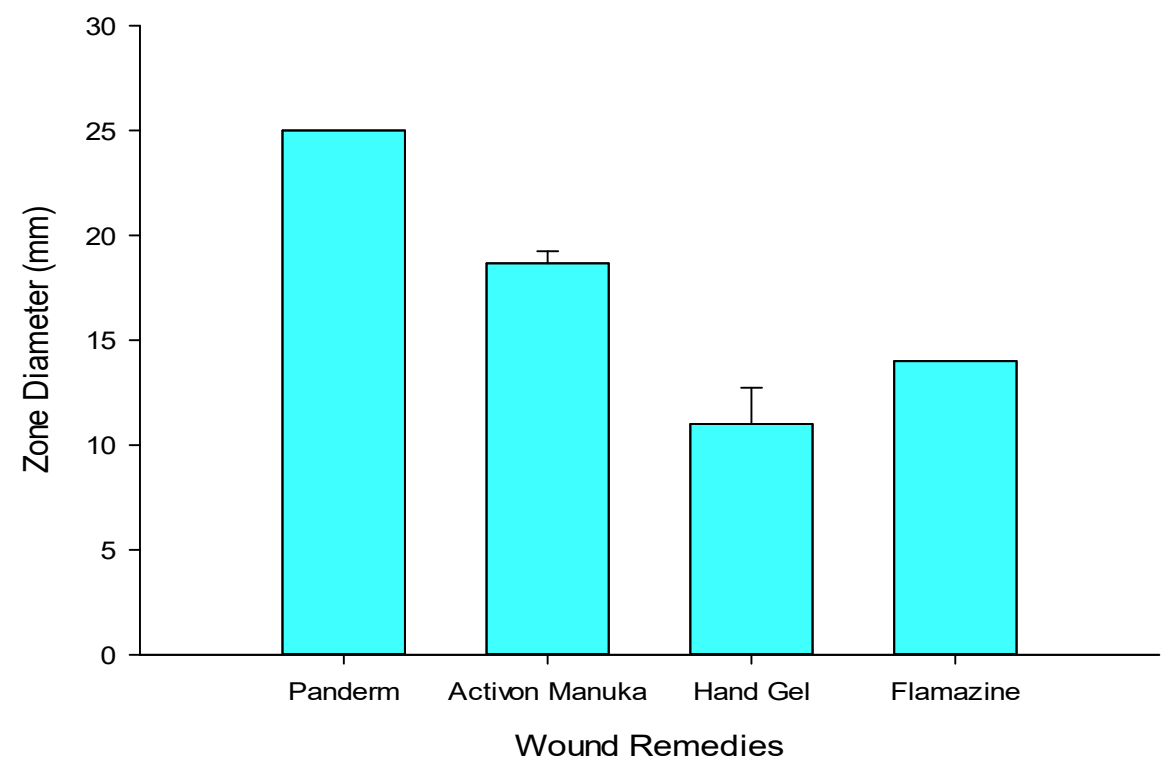

Figure 3. The effect of wound treatments on the planktonic Staphylococcus aureus.

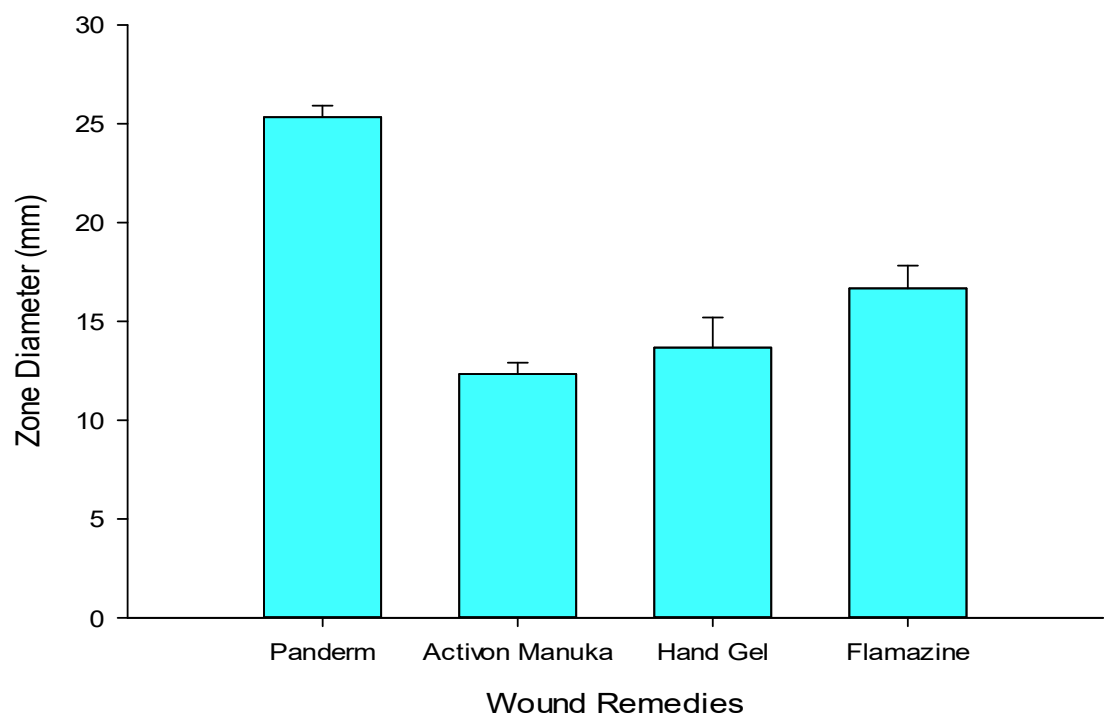

Figure 4. The effect of wound treatments on planktonic Pseudomonas aeruginosa 
c. Activity of some wound dressings on the bacterial biofilm of Staphylococcus aureus and

Pseudomonas aeruginosa

The killing activities of three types of dressings were tested against biofilms of $S$. aureus and $P$. aeruginosa. Biofilms were tested in three different stages of development, before biofilm formation, and at 24 and 48 hours after formation.

Against $S$. aureus, a variety of antibacterial dressings of the three types of biofilms brought about complete biofilm inhibition after 0 , (representing biofilm initiation) 24 and 48 hours. In contrast the silver dressings achieved only $99 \%$ and $86 \%$ inhibition of biofilm formation after 24 and 48 hours (Figure 5). Against Pseudomonas aeruginosa, all of the dressings killed all the biofilm formed at 0,24 and 48 hours except for the NAD dressing (Figure 6). Similar results were obtained by Percival et al., (2008). However, this finding did not correlate well with in vivo observations (Heggers et al., 2005).
Kostenko et al., 2010 claimed that silver content within medical dressings in general is insufficient to eliminate chronic wound biofilms, where the complete killing happens when a silver concentration is greater by $10-100$ times than that used to treat the planktonic bacteria. It was also reported that in vitro $P$. aeruginosa biofilm can be successfully eradicated with silver concentrations of $5-10 \mu \mathrm{g} / \mathrm{ml}$ (Bjarnsholt et al., 2007). The biofilm is a population that is very hard to eliminate because the cells inside the biofilm are inert and the atmosphere is anaerobic and acidic, so that antimicrobial agents do not work effectively (Davey and O'Toole, 2000, Davies, 2003, Sternberg et al., 1999). Moreover, the diversity of bacterial species within wounds makes the exchange of drug resistance determinants easier between bacterial cells (Cookson, 2005, Davies, 1994). So more than one antibiotic with high concentration is needed based on a study by Hill et al. (2010) who reported that a mixture of $S$. aureus and Ps. aeruginosa biofilm was not treated in vitro by using high concentrations of Flucloxacillin $(15 \mathrm{mg} / \mathrm{L})$ or Ciprofloxacin $(5 \mathrm{mg} / \mathrm{L})$.

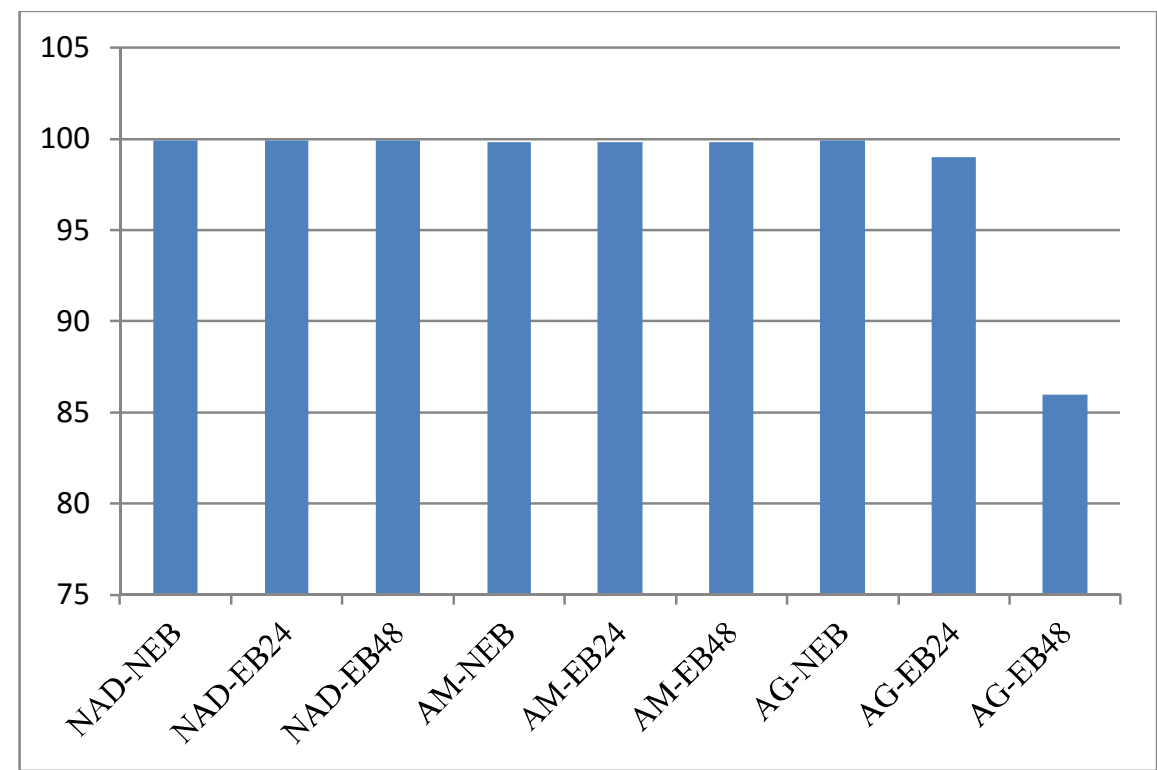

(Figure 5): The killing activity of selected wound dressings on the biofilm of $S$. aureus. $\mathbf{A g}=\mathrm{Askina}^{\odot} \mathrm{Calgitrol}^{\odot} \mathrm{Ag}$ NAD $=$ Actilite $^{\mathscr{\odot}}$ (a non-adherent dressing with Activon Manuka honey), $\mathbf{M}=$ Algivon $^{\mathcal{C}}$ (alginate dressing impregnated with 100\% Manuka honey), NEB= Non Established Biofilm, EB24= Established Biofilm for 24 hours, EB48= Established Biofilm for 48 hours 
Effects of Selected Wound Dressings and Remedies on Planktonic Bacteria and Bacterial Biofilms of Staphylococcus aureus and Pseudomonas aeruginosa

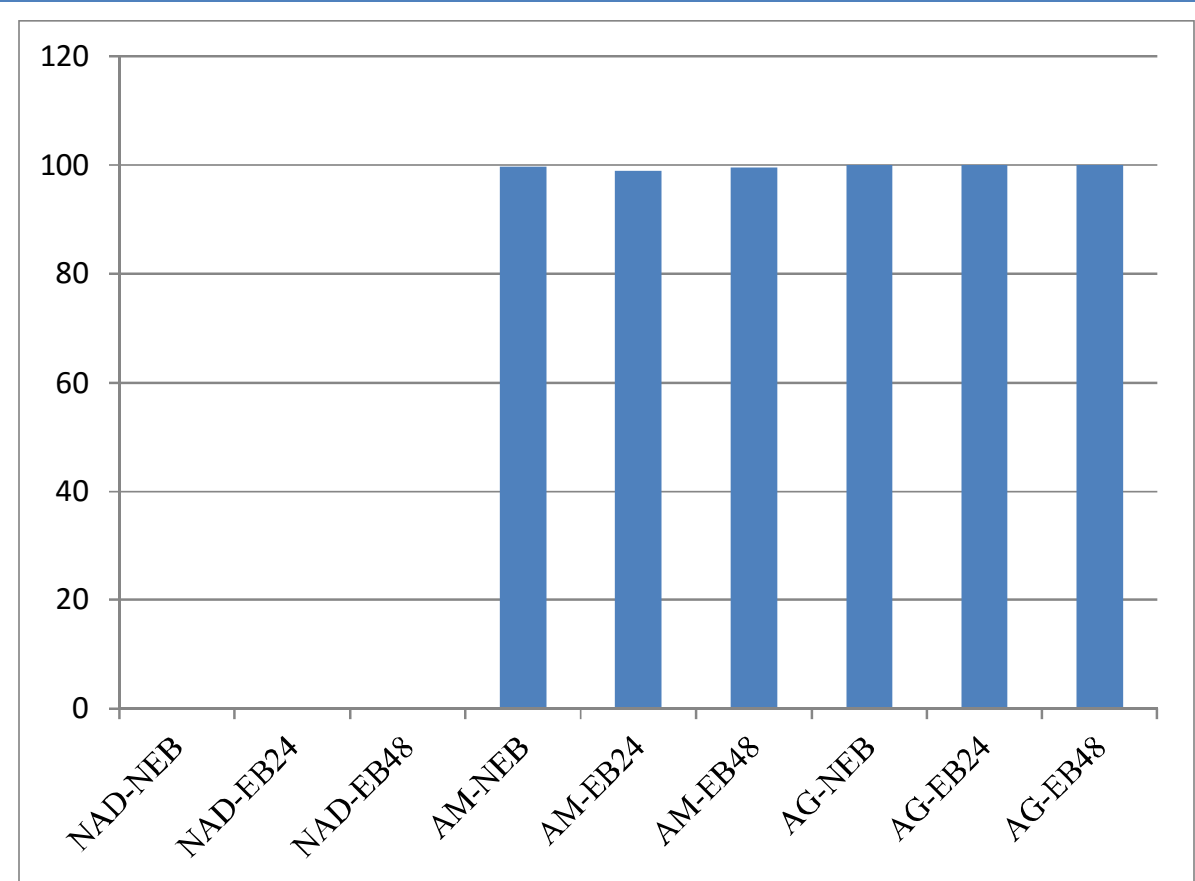

Figure 6. The killing activity of some dressings on the biofilm of $P$. aeruginosa. $\mathbf{A g}=\mathrm{Askina}^{\circ} \mathrm{Calgitrol}^{\circ} \mathrm{Ag}, \mathbf{N A D}$ $=$ Actilite $^{\mathscr{O}}$ (a non-adherent dressing with Activon Manuka honey), $\mathbf{M}=$ Algivon $^{\mathscr{}}$ (alginate dressing impregnated with 100\% Manuka honey), NEB= Non Established Biofilm, EB24= Established Biofilm for 24 hours, EB48= Established Biofilm for 48 hours

\section{d. Effect of wound treatments on the bacterial biofilm}

Figures 7 and 8 show the effects of wound remedies on bacterial biofilms of $S$. aureus and P. aerugnosa. Panaderm cream, which is a mixture of different antibiotics, showed the highest activity against the two bacterial species tested. The antimicrobial activity of the hand gel was the weakest. In contrast, Flamazine, and Activon have approximately similar activity. Among previously used antimicrobial agents, honey is gaining popularity among doctors and medical specialists. In a comparative study between ampicillin ointment, saline treatment and honey dressing, honey was the leading antibacterial agent showing least epithelization, inflammation and the most active fibroblastic and angioblastic activity (Gupta, 1992). In a similar observation honey was found to be more active on multidrug resistant bacteria such as methicillin resistant $S$. aureus (MRSA) than both antibiotics and antiseptics in the treatment of wounds (Blaser et al., 2007a). The results of the hand gel correlate well with Pietsch (2001) allegation when he claimed that alcoholic gels are not always preferable in hand sterilization as they are not compatible with the European standard for hand disinfectants (EN 1500). In vitro, Al Zahrani and Baghdadi, (2012) showed that only two out of seven tested types of hand sanitizers were active and can be used as anti-bacterial agent. 
Effects of Selected Wound Dressings and Remedies on Planktonic Bacteria and Bacterial Biofilms of Staphylococcus aureus and Pseudomonas aeruginosa

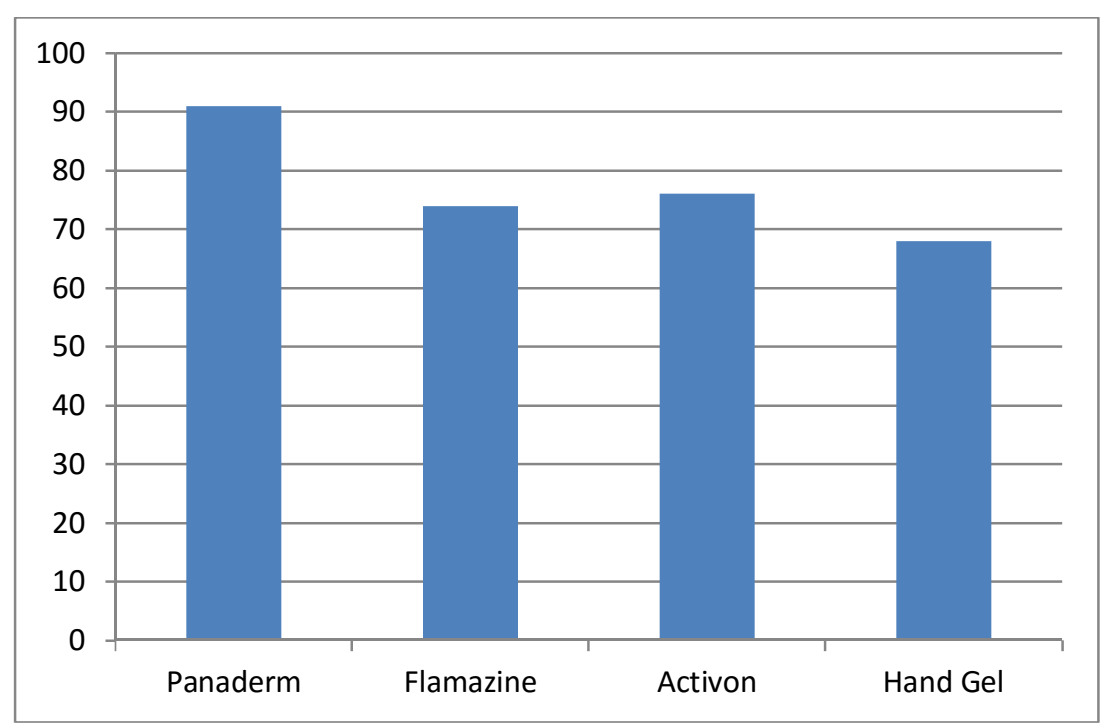

Figure 7. Effect of various cream products and a hand gel on biofilm of S. aureus.

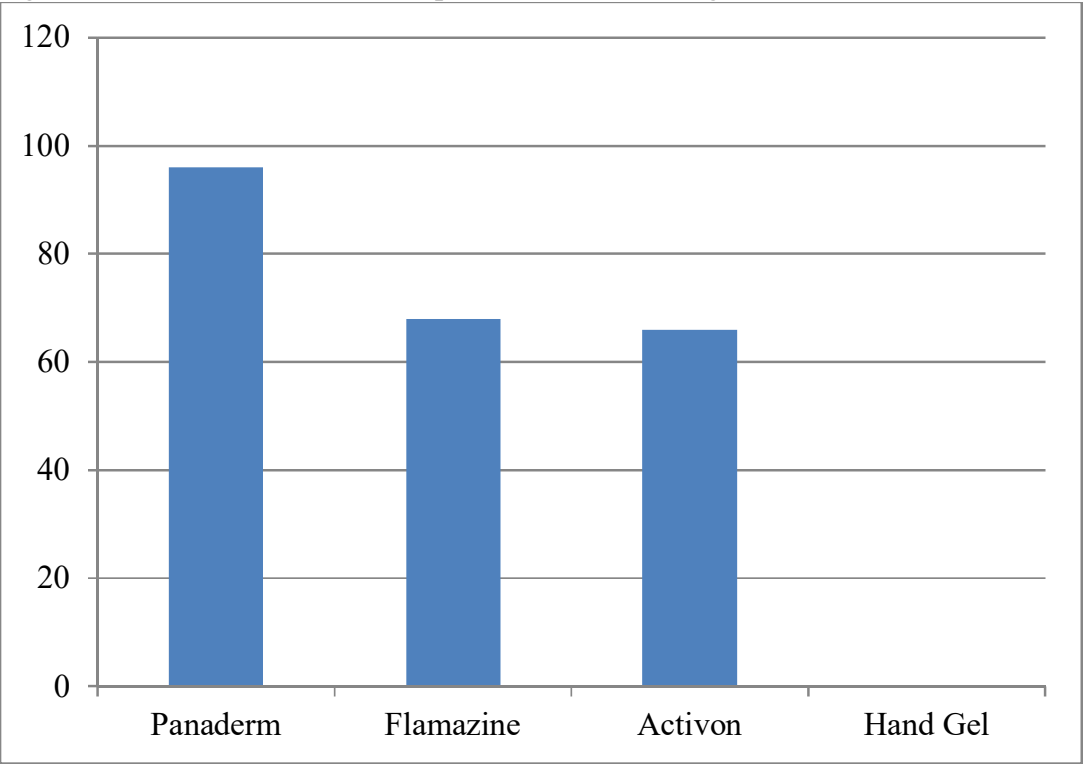

Figure 8. Effect of various antibacterial cream products and a hand gel on biofilm of $P$. aeruginosa

\section{CONCLUSIONS}

Results obtained from the present study indicate that silver and honey exhibited good outcomes as antimicrobial agents for wound dressings. The use of silver to dress wounds causes inhibition of bacterial growth, because silver inhibits bacterial respiration and the activities of enzymes required for viability. Further, silver causes inhibition of bacterial biofilms. Similarly, honey is an active dressing agent for treating wounds because its acidity, hydrogen peroxide content and methylglyoxal which can be found in Manuka honey. We strongly recommend using silver and honey as dressing agents, because they reduce inflammation, accelerate healing, kill planktonic bacteria, and inhibit the growth of the bacterial biofilms.

\section{WORKS CITED}

1) Al Zahrani, S. and Baghdadi, M.(2012). Evaluation of the efficiency of non-alcoholic-hand gel sanitizers products as an antibacterial. Nature Sci.10, 15-20.

2) Benbow, M.(2005). Evidence-based wound management, London, Whurr.

3) Bjarnsholt, T., Kirketerp-Moller, K., Jensen, P. O., Madsen, K. G., Phipps, R., Krogfelt, K., Hoiby, N. and Givskov, M.(2008). Why chronic wounds will not heal: a novel hypothesis. Wound Rep Regen, 16, 2-10. http://dx.doi.org/10.1111/j.1524-475x.2007.00283.x

4) Bjarnsholt, T., Kirketerp-Moller, K., Kristiansen, S., Phipps, R., Nielsen, A. K., Jensen, P. O.,Hoiby, N. and Givskov, M.(2007). Silver against Pseudomonas aeruginosa biofilms. 
APMIS, 115, 921-8. http://dx.doi.org/10.1111/j.16000463.2007.apm_646.x

5) Blaser, G., Santos, K., Bode, U., Vetter, H. and Simon, A. (2007a). Effect of medical honey on wounds colonised or infected with MRSA. J Wound Care, 16, 325- 8. http://dx.doi.org/10.12968/jowc.2007.16.8.27851

6) Chaw, K. C., Manimaran, M. and Tay, F. E. (2005). Role of silver ions in destabilization of intermolecular adhesion forces measured by atomic force microscopy in Staphylococcus epidermidis biofilms. Antimicrob Agents Chemother, 49, 4853-9. http://dx.doi.org/10.1128/aac.49.12.4853-4859.2005

7) Cookson, B.(2005). Clinical significance of emergence of bacterial antimicrobial resistance in the hospital environment. J Appl Microbiol, 99, 989-96. http://dx.doi.org/10.1111/j.1365-2672.2005.02693.x

8) Davey, M. E. and OToole G. A.(2000). Microbial biofilms: from ecology to molecular genetics. Microbiol Mol Biol Rev, 64, 847-67. http://dx.doi.org/10.1128/mmbr.64.4.847867.2000

9) Davies, D. (2003). Understanding biofilm resistance to antibacterial agents. Nat Rev Drug Discov, 2, 114-22. http://dx.doi.org/10.1038/nrd1008

10) Davies, J. (1994). Inactivation of antibiotics and the dissemination of resistance genes. Science, 264, 375-82. http://dx.doi.org/10.1126/science.8153624

11) Davies, S. C., Ricotti, C., Cazzaniga, A., Welsh, E., Eaglstein, W. H. and Mertz, P. M.(2008). Microscopic and physiologic evidence for biofilm-associated wound colonization in vivo. Wound Rep Regen, 16, 23-9. http://dx.doi.org/10.1111/j.1524-475x.2007.00303.x

12) Dunford, C. E. and Hanano, R.(2004). Acceptability to patients of a honey dressing for non-healing venous leg

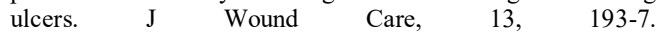
http://dx.doi.org/10.12968/jowc.2004.13.5.26614

13) Escriche, I., Kadar, M., Juan-Borras, M. and Domenech, E.(2013). Suitability of antioxidant capacity, flavonoids and phenolic acids for floral authentication of honey. Impact of industrial thermal treatment. Food Chem, 142, 135-43. http://dx.doi.org/10.1016/j.foodchem.2013.07.033

14) Gethin, G.and Cowman, S.and Conroy, R. M.(2008). The impact of Manuka honey dressings on the surface $\mathrm{pH}$ of chronic wounds. Int Wound J, 5, 185-94. http://dx.doi.org/10.1111/j.1742-481x.2007.00424.x

15) Gupta, S., Singh, H., Varshney, A. and Prakash, P. (1992). Therapeutic efficacy of honey in infected in buffaloes. Ind. J.f An. Sci.62, 521-3.

16) Heggers, J., Goodheart, R. E., Washington, J., Mccoy, L., Carino, E., Dang, T., Edgar, P., Maness, C. and Chinkes, D.(2005). Therapeutic efficacy of three silver dressings in an infected animal model. J Burn Care Rehabil, 26, 53-6. http://dx.doi.org/10.1097/01.bcr.0000150298.57472.26

17) Hill, K. E., Malic, S., Mckee, R., Rennison, T., Harding, K. G., Williams, D. W. and Thomas, D. W.(2010). An in vitro model of chronic wound biofilms to test wound dressings and assess antimicrobial susceptibilities. J Antimicrob Chemother, 65, 1195-206. http://dx.doi.org/10.1093/jac/dkq105

18) James, G. A., Swogger, E., Wolcott, R., Pulcini, E., Secor, P., Sestrich, J., Costerton, J. W. and Stewart, P. S.( 2008). Biofilms in chronic wounds. Wound Rep Regen, 16, 37-44. http://dx.doi.org/10.1111/j.1524-475x.2007.00321.x
19) Klueh, U., Wagner, V., Kelly, S., Johnson, A. and Bryers, J. D.(2000). Efficacy of silver-coated fabric to prevent bacterial colonization and subsequent device-based biofilm formation. J Biomed Mater Res, 53, 621-31. http://dx.doi.org/10.1002/1097-4636(2000)53:6\%3C621::aidjbm2\%3E3.0.co;2-q

20) Kostenko, V., Lyczak, J., Turner, K., Martinuzzi, R. J. (2010). Impact of Silver-containing wound dressings on bacterial biofilm viability and susceptibility to antibiotics during prolonged treatment. Antimicrob Agents Chemother. 54(12): 5120-31. http://dx.doi.org/10.1128/aac.00825-10

21) Kwakman, P. H. and Zaat, S. A.(2012). Antibacterial components of honey. IUBMB Life, 64, 48-55. http://dx.doi.org/10.1002/iub.578

22) Kwakman, P. H., Te Velde, A. A., De Boer, L., Speijer, D., Vandenbroucke- Grauls, C. M. and Zaat, S. A.(2010). How honey kills bacteria. FASEB J, 24, 2576- 82. $\square$ http://dx.doi.org/10.1096/fj.09-150789

23) Lansdown, A. B. (2002). Silver. I: Its antibacterial properties and mechanism of action. J Wound Care, 11, 125-30. http://dx.doi.org/10.12968/jowc.2002.11.4.26389

24) Marchetti, M. G., Kampf, G., Finzi, G. and Salvatorelli, G.(2003). Evaluation of the bactericidal effect of five products for surgical hand disinfection according to prEN 12054 and prEN 12791. J Hosp Infect, 54, 63-7. http://dx.doi.org/10.1016/s0195-6701(03)00039-2

25) Merritt, J. H., Kadouri, D. E. and O'Toole, G. A. (2005) Growing and analyzing static biofilms. Curr Protoc Microbiol, Chapter 1, Unit 1B1. http://dx.doi.org/10.1002/9780471729259.mc01b01s00

26) Moore, O. A., Smith, L. A., Campbell, F., Seers, K., Mcquay, H. J. and Moore, R. A. (2001). Systematic review of the use of honey as a wound dressing. BMC Complement Altern Med, 1, 2. http://dx.doi.org/10.1186/1472-6882-1-2

27) Percival, S. L., Bowler, P. and Woods, E. J. (2008). Assessing the effect of an antimicrobial wound dressing on biofilms. Wound Rep Regen, 16, 52-7. http://dx.doi.org/10.1111/j.1524-475x.2007.00350.x

28) Percival, S. L., Bowler, P.G. and Dolman, J.(2007) Antimicrobial activity of silver- containing dressings on wound microorganisms using an in vitro biofilm model. Int Wound J, 4, 186-91. http://dx.doi.org/10.1111/j.1742481x.2007.00296.x

29) Pietsch, H. (2001). Hand antiseptics: rubs versus scrubs, alcoholic solutions versus alcoholic gels. J Hosp Infect, 48, S33-S36 http://dx.doi.org/10.1016/s0195-6701(01)90010-6

30) Sharp, A. (2009). Beneficial effects of honey dressings in wound management. Nurs Stand, 24, 66-8, 70, 72 passim. $\square$ http://dx.doi.org/10.7748/ns2009.10.24.7.66.c7331

31) Sternberg, C., Christensen, B. B., Johansen, T., Toftgaard Nielsen, A., Andersen, J. B., Givskov, M. and Molin, S.(1999). Distribution of bacterial growth activity in flowchamber biofilms. Appl Environ Microbiol, 65, 4108-17.

32) Topham, J.(2002). Why do some cavity wounds treated with honey or sugar paste heal without scarring? J Wound Care, 11, 53-5. http://dx.doi.org/10.12968/jowc.2002.11.2.26372

33) Wirtanen, G., Salo, S., Helander, I. M. and MattilaSandholm, T. (2001). Microbiological methods for testing disinfectant efficiency on Pseudomonas biofilm. Colloid Surf B Biointerfaces, 20, 37-50. http://dx.doi.org/10.1016/s09277765(00)00173-9 